\title{
A systematic review of risk factors associated with near-fatal and fatal asthma
}

\author{
GG Alvarez MD MPH FRCPC, M Schulzer MD PhD, D Jung BSc, JM FitzGerald MB MD FRCPI FRCPC
}

GG Alvarez, M Schulzer, D Jung, JM FitzGerald. A systematic review of risk factors associated with near-fatal and fatal asthma. Can Respir J 2005;12(5):265-270.

BACKGROUND: Asthma mortality and morbidity continue to be a serious global problem. Systematic reviews provide an opportunity to review risk factors in detail.

OBJECTIVE: To review all of the literature for risk factors associated with near-fatal asthma (NFA) and fatal asthma (FA).

METHODS: A literature search from 1960 to January 2004 in MEDLINE and EMBASE was conducted. Studies were included based on the following criteria: NFA was defined as an asthma exacerbation resulting in respiratory arrest requiring mechanical ventilation or a partial pressure of $\mathrm{CO}_{2}$ of at least $45 \mathrm{mmHg}$ or asthma resulting in death (FA); the study reported the number of cases (NFA and/or FA) and asthmatic controls; there was explicit reporting of risk factors; cases that were adult and pediatric in nature; and all study types. Studies that included patients with chronic obstructive pulmonary disease were excluded.

RESULTS: Four hundred and three articles were identified, of which 27 met the inclusion criteria. Increased use of medications such as betaagonists via metered dose inhalers $(\mathrm{OR}=1.67,95 \% \mathrm{CI} 0.99$ to 2.84 , $\mathrm{P}=0.057)$ and nebulizers $(\mathrm{OR}=2.45,95 \%$ CI 1.52 to $3.93, \mathrm{P}=0.0002)$, oral steroids $(\mathrm{OR}=2.71,95 \% \mathrm{CI} 1.34$ to $5.51, \mathrm{P}=0.006)$ and oral theophylline $(\mathrm{OR}=2.02,95 \% \mathrm{CI} 1.03$ to $3.98, \mathrm{P}=0.04)$ and a history of hospital $(\mathrm{OR}=2.62,95 \% \mathrm{CI} 1.04$ to $6.58, \mathrm{P}=0.04)$ and/or intensive care unit $(\mathrm{OR}=5.14,95 \% \mathrm{CI} 1.91$ to $13.86, \mathrm{P}=0.001)$ admissions and mechanical ventilation $(\mathrm{OR}=6.69,95 \% \mathrm{CI} 2.80$ to $15.97, \mathrm{P}=0.0001)$ due to asthma were predictors of NFA and FA. Prior emergency department assessment did not confer a greater risk of NFA and FA $(\mathrm{OR}=1.13,95 \% \mathrm{CI} 0.43$ to $2.92, \mathrm{P}=0.810)$. The use of inhaled corticosteroids (ICS) measured in a dose-independent fashion (did the patient take ICS previously; yes or no) inferred equivocal risk of NFA and $\mathrm{FA}(\mathrm{OR}=1.31,95 \% \mathrm{CI} 0.83$ to $2.05, \mathrm{P}=0.25)$. However, two studies measured the use of ICS in a dose-dependent fashion (ie, measured the number of prescriptions filled within the previous six to 12 months). Both studies showed a trend toward a protective effect against FA. One study showed that the premature cessation of ICS can hasten death.

CONCLUSIONS: In the present study, risk factors of NFA and FA have been more accurately defined. Clinicians should identify patients with these characteristics to reduce their risk of NFA and FA. Further research should focus on quantifying the impact of risk factors on asthma deaths.

Key Words: Fatal asthma; Near-fatal asthma; Risk factors; Systematic review

\section{Revue systématique des facteurs de risque associés à l'asthme gravissime et à l'asthme fatal}

HISTORIQUE : La mortalité et la morbidité liées à l'asthme continuent de représenter un grave problème global. Les revues systématiques donnent aux chercheurs la possibilité d'étudier en détails les facteurs de risque.

OBJECTIF : Revoir toute la littérature pour déterminer quels sont les facteurs de risque associés à l'asthme gravissime (AG) et à l'asthme fatal (AF).

MÉTHODES : Une interrogation de la littérature publiée entre 1960 et janvier 2004 a été effectuée sur MEDLINE et EMBASE. Les études ont été incluses selon les critères suivants : l'asthme gravissime se définissait comme une exacerbation de l'asthme ayant entraîné un arrêt respiratoire nécessitant une ventilation mécanique, une pression partielle du $\mathrm{CO}_{2}$ supérieure à $45 \mathrm{~mm} \mathrm{Hg}$, ou un asthme entraînant la mort (AF); les études mentionnaient le nombre de sujets souffrant d'AG et/ou d'AF et le nombre de sujets asthmatiques témoins; elles énonçaient de façon explicite les facteurs de risque et les caractéristiques propres aux adultes et aux enfants; et regroupaient tous les types de protocoles. Les études auxquelles participaient des patients atteints de maladie pulmonaire obstructive chronique étaient exclues.

RÉSULTATS : Quatre cent trois articles ont été recensés, dont 27 répondaient aux critères d'inclusion. L'utilisation accrue de médicaments, comme les bêta-agonistes par aérosols-doseurs ( $R R=1,67$ IC $95 \% ; 0,99$ à 2,84; $\mathrm{p}=0,057$ ) et nébuliseurs ( $R R=2,45 ; \operatorname{IC~} 95 \% ; 1,52$ à 3,93; $\mathrm{p}=0,0002)$, les corticostéroïdes oraux $(\mathrm{RR}=2,71$; IC $95 \% ; 1,34$ à 5,$51 ; \mathrm{p}=0,006)$ et la théophylline orale $(R R=2,02 ;$ IC $95 \% ; 1,03$ à 3,98; $p=0,04)$ et des antécédents d'hospitalisation ( $R R=2,62$; IC $95 \% ; 1,04$ à 6,58; $\mathrm{p}=0,04)$ et/ou de séjours aux soins intensifs ( $R R=5,14$; IC $95 \%$; 1,91 à 13,86; $\mathrm{p}=0,001)$ et de ventilation mécanique $(\mathrm{RR}=6,69 ; \mathrm{IC} 95 \% ; 2,80$ à 15,97 ; $\mathrm{p}=0,0001)$ en raison de l'asthme ont constitué des facteurs de prévisibilité de l'AG et de l'AF. Une consultation préalable aux urgences ne conférait pas un risque accru d'AG et d'AF ( $R R=1,13$; IC $95 \%$; 0,43 à 2,92; $p=0,810)$. L'utilisation de corticostéroïdes par inhalation (CSI) indépendamment de la dose (le patient avait-il ou non pris des CSI?) était associée à une inférence équivoque de risque d'AG et d'AF $(R R=1,31 ;$ IC $95 \% ; 0,83$ à 2,05; $\mathrm{p}=0,25)$. Par contre, deux études ont mesuré le recours aux CSI de façon dose-dépendante (c. à d., nombre d'ordonnances exécutées au cours des six à douze derniers mois). La tendance dégagée par ces deux études suggérait un effet protecteur contre l'AF. Une étude a montré que l'arrêt prématuré des CSI pouvait hâter le décès.

CONCLUSION : Dans la présente étude, les facteurs de risque d'AG et d'AF ont été définis avec plus de précision. Les cliniciens doivent identifier les patients qui présentent ces caractéristiques afin de réduire le risque d'AG et d'AF. Les recherches à venir devront s'attarder à quantifier l'impact des facteurs de risque sur la mortalité liée à l'asthme.

University of British Columbia, Vancouver General Hospital Respirology Division and the Centre for Clinical Epidemiology and Evaluation, Vancouver, British Columbia

Correspondence: Dr JM FitzGerald, Vancouver General Hospital, 7th Floor - 828 West 10th Avenue, Vancouver, British Columbia V5Z 1 L8.

Telephone 604-875-4122 ext 54565, fax 604-875-4719, e-mail markf@interchange.ubc.ca 
A sthma mortality and morbidity continue to be a serious global problem. Identification of risk factors associated with near-fatal asthma (NFA) or fatal asthma (FA) have historically assisted physicians in managing asthma patients. Risk factors provide a valuable tool to predict which patients are at a higher risk for a fatal episode and, thus, allow the potential for earlier intervention in management to prevent mortality and morbidity due to asthma. There have been many risk factors identified in the published literature. We have previously reviewed the risk factors of NFA and FA in general $(1,2)$. We have also identified a number of key risk factors in one of the first prospective studies (3); specifically, the impact of psychological factors on NFA (4), differences in outcome depending on the type of mechanical ventilation used for NFA (5), and differences in computed tomography imaging of the airways in NFA compared with both control subjects and patients with asthma and no history of NFA (6). We have also identified the challenge of delivering asthma education to NFA patients (7). We set out to review all of the existing literature for risk factors associated with NFA and FA, and to determine which of these may have stronger associations with mortality and morbidity.

\section{METHODS}

A literature search from 1960 to January 2004 in MEDLINE and EMBASE was conducted. MeSH headings used in the search included 'nonfatal asthma', 'fatal asthma' and 'risk factors'. Citations from published reviews, the original articles, expert opinion and the authors' personal extensive bibliography were also searched. Studies were included based on the following criteria: NFA was defined as an asthma exacerbation resulting in respiratory arrest requiring mechanical ventilation or a partial pressure of $\mathrm{CO}_{2}$ of at least $45 \mathrm{mmHg}$ or asthma resulting in death (FA); the study reported the number of cases (NFA and/or FA) and controls; there was explicit reporting of risk factors; cases that were adult and pediatric in nature; and all study types. The following studies were excluded: case series because they do not contain controls; studies that included patients with chronic obstructive pulmonary disease (COPD); studies that contained only patients older than 65 years of age were excluded to minimize COPD overlap (over $80 \%$ of patients included in the analysis were younger than 65 years of age [data not shown]); and studies in a language other than English. In reviewing the literature, a number of important risk factors were identified, including perception of dyspnea, economic risk factors and psychological factors. The outcomes reported for these particular risk factors did not allow for the combination of these studies in a systematic manner; therefore, the data will be presented elsewhere.

\section{Preset definitions}

NFA was defined as an asthma exacerbation resulting in respiratory arrest requiring mechanical ventilation or a partial pressure of $\mathrm{CO}_{2}$ of at least $45 \mathrm{mmHg}(8,9)$. NFA and FA subjects were presumed to be part of the same pathophysiological spectrum $(10,11)$. The diagnosis of asthma was defined according to the criteria of the American Thoracic Society (12).

\section{Statistical methods}

A meta-analytic integration of the data was carried out using the 27 articles identified. For each item to be combined, pooled ORs were derived using logarithmic transformations, with inverse variance weighting. Q-tests for homogeneity were carried out. Random effects were used when the homogeneity hypothesis was rejected at $\mathrm{P}<0.1$. Calculations and forest plots were performed with the Comprehensive Meta-Analysis software (Biostat, USA) (13).

\section{RESULTS}

The authors (GGA and JMF) identified 403 articles from several comprehensive searches. One of the authors (GGA) identified 67 case control studies that met the inclusion criteria. The results of the systematic search identified only case control studies. To improve the homogeneity of the controls in the case control studies, a preset control definition was constructed. Hospital controls were defined as patients admitted in the previous two years, currently admitted or seen in the emergency department (ED) for their asthma. For the purposes of the analysis, the NFA/FA groups in all of the studies were compared with hospital controls.

Data were abstracted by two observers (GGA and JMF) using a standardized data extraction sheet that was developed for the purpose of the study. Data extraction sheets were filled out for each article. Differences were resolved by consensus. Thirty-four articles were excluded based on the rigorous application of the inclusion and exclusion criteria. Twenty-three articles were case series with no controls, three articles published the same data twice and three articles combined COPD and asthma patients. The remaining four articles were excluded based on a variety of reasons, including being an editorial, examining the onset of asthma attacks, comparing intrinsic and extrinsic asthma, and examining computed tomography scan comparisons. A meta-analytic integration of the data was carried out using the remaining 27 articles. The data were analyzed by separating NFA and FA to see if differences existed between the two entities; however, no differences were detected (data not shown). This finding was consistent with current ideas surrounding the issue of NFA and FA being a continuous spectrum of the same entity $(10,11)$. Risk factors that were identified included medications, asthma history, atopy and smoking history.

\section{Beta-agonists}

\section{MEDICATIONS}

Inhaled (via a metered-dose inhaler) beta-agonist: Ten studies, which included 3606 patients, examined the impact of inhaled beta-agonist use on the risk of NFA/FA. The combined data demonstrated that the use of beta-agonists via a metered-dose inhaler (MDI) was associated with a greater risk of NFA/FA $(\mathrm{OR}=1.67,95 \%$ CI 0.99 to $2.84, \mathrm{P}=0.057)$ (Figure 1$)$.

Nebulized beta-agonist: Three studies, which included 1525 patients, examined the impact of nebulized beta-agonists on the outcomes of interest. The use of beta-agonists via a nebulizer was associated with a greater risk of NFA/FA $(\mathrm{OR}=2.45$, 95\% CI 1.52 to 3.93, $\mathrm{P}=0.0002$ ) (Figure 2).

Oral beta-agonist: Six studies, which included 1905 patients, examined the impact of oral beta-agonists. The use of betaagonists via the oral route was equivocal in its association. A trend toward an increased risk of NFA/FA was observed $(\mathrm{OR}=1.20,95 \% \mathrm{CI} 0.93$ to $1.55, \mathrm{P}=0.160)$ (Figure not shown).

\section{Corticosteroids}

Inhaled (via MDI) corticosteroids: Thirteen studies, which included 3063 patients, examined the impact of inhaled corticosteroid (ICS) use on the outcomes of interest. Exposure to inhaled corticosteroids inferred an equivocal risk of NFA/FA. A trend toward an increased risk of NFA/FA with ICS exposure was 


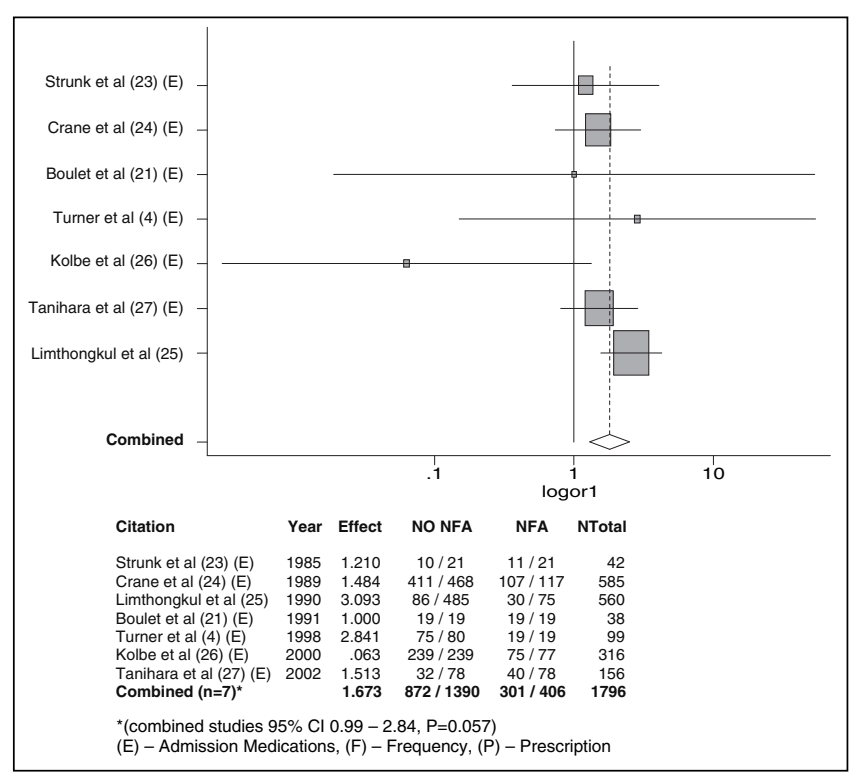

Figure 1) Meta-analytic integration of inhaled short acting beta-agonists and near-fatal asthma (NFA)/fatal asthma studies. Data adapted from references 4, 21 and 23-27

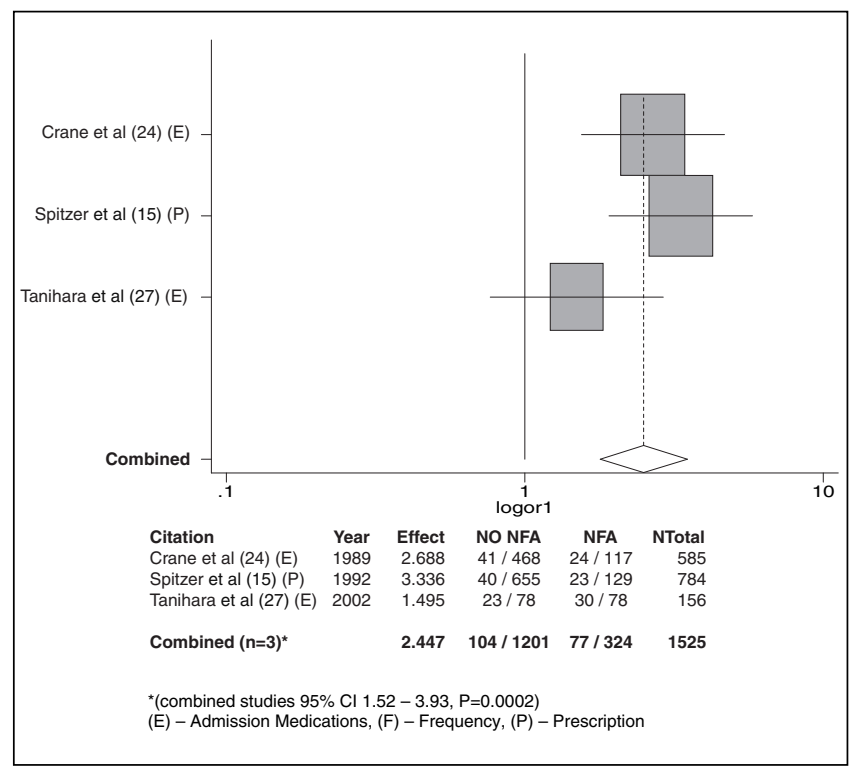

Figure 2) Meta-analytic integration of nebulized beta-agonists and near-fatal asthma (NFA)/fatal asthma studies. Data adapted from references 15,24 and 27

observed ( $\mathrm{OR}=1.03,95 \% \mathrm{CI} 0.83$ to $2.05, \mathrm{P}=0.25)$ (Figure 3). The funnel plot for ICS was quite symmetrical and did not suggest the presence of any marked publication bias (not shown). Oral corticosteroids: Twelve studies, including 2855 patients, examined the impact of oral corticosteroids on the outcomes of interest. The use of oral steroids was associated with an increased risk of NFA/FA (OR=2.30, 95\% CI 1.14 to 4.66 , $\mathrm{P}=0.02$ ) (Figure 4).

\section{Theophylline}

Seven studies, which included 2852 patients, examined oral theophylline. The use of oral theophylline was associated with an increased risk of NFA/FA (OR $=2.02,95 \%$ CI 1.03 to 3.98, $\mathrm{P}=0.04$ ) (Figure not shown).

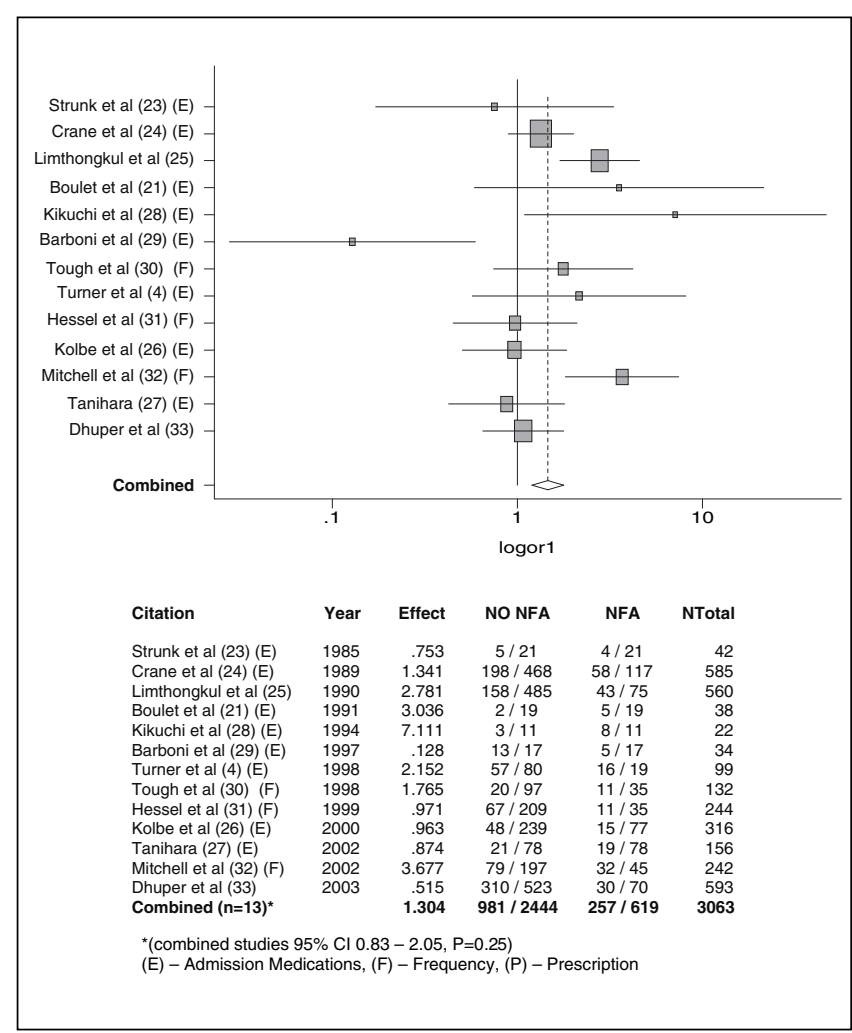

Figure 3) Meta-analytic integration of inhaled corticosteroids and near-fatal asthma (NFA)/fatal asthma studies without Suissa et al (18) and Lanes et al (19). Data adapted from references 4, 21 and 23-33

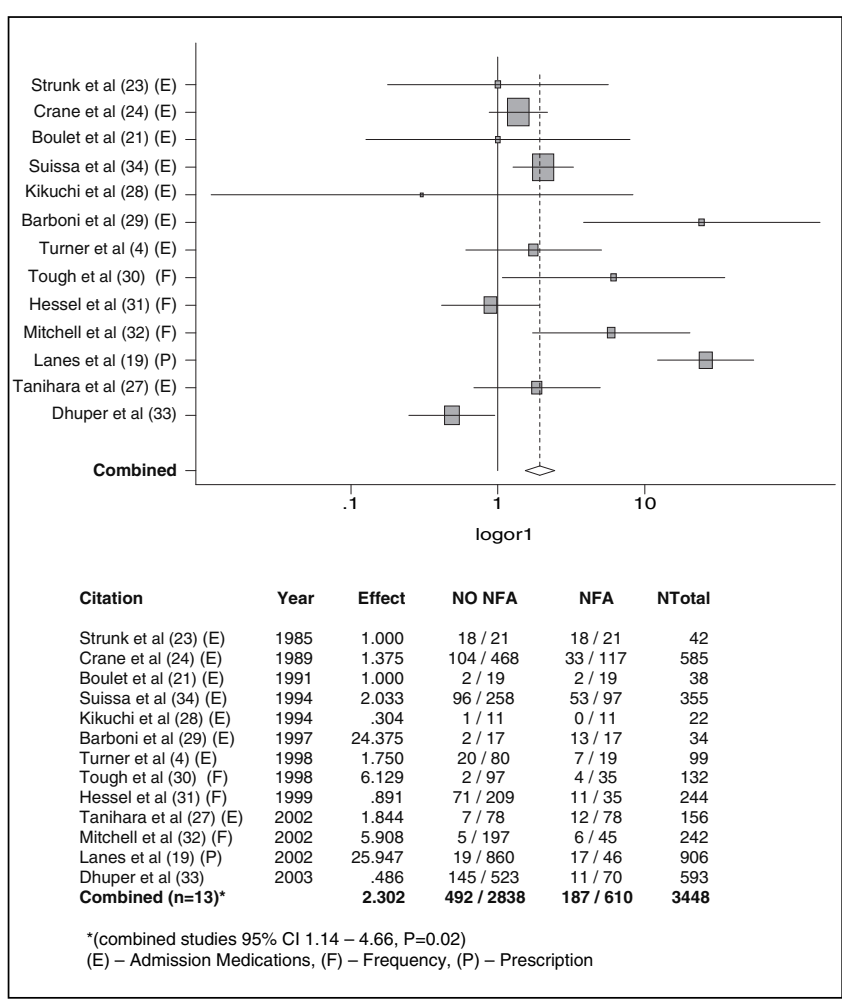

Figure 4) Meta-analytic integration of oral corticosteroids and nearfatal asthma (NFA)/fatal asthma studies. Data adapted from references $4,19,21,23,24$ and 27-34 


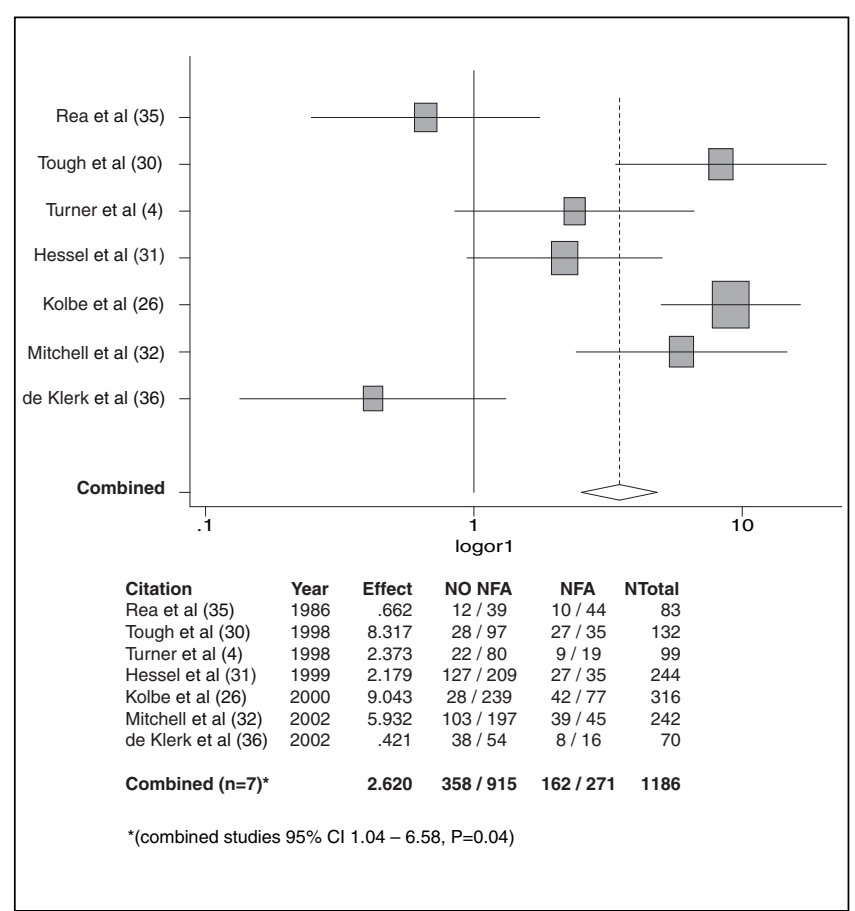

Figure 5) Meta-analytic integration of hospital admissions and nearfatal asthma (NFA)/fatal asthma studies. Data adapted from references 26, 30-32, 35 and 36

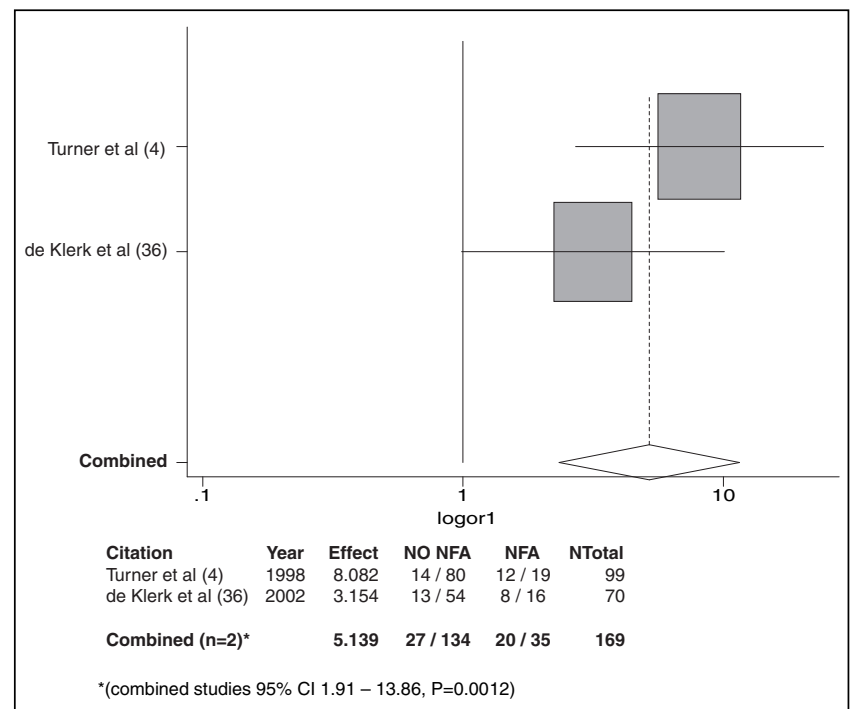

Figure 6) Meta-analytic integration of intensive care unit admissions and near-fatal asthma (NFA)/fatal asthma studies. Data adapted from references 4 and 36

\section{ASTHMA HISTORY}

\section{ED assessment}

Five studies, which included 700 patients, examined the impact of having a history of visiting an ED for acute asthma. Prior ED assessment did not confer a greater risk of NFA/FA $(\mathrm{OR}=1.13$, 95\% CI 0.43 to 2.92, $\mathrm{P}=0.810$ ) (Figure not shown).

\section{Admission to hospital}

Seven studies, which included 1186 patients, examined previous admission to hospital as a risk factor. A history of admission to

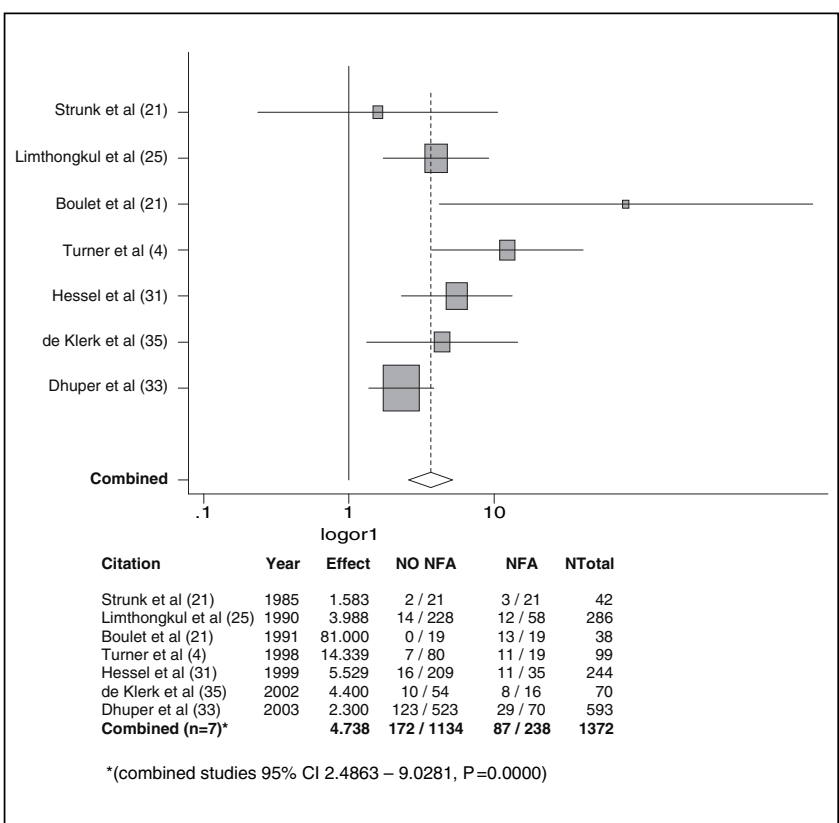

Figure 7) Meta-analytic integration of mechanical ventilations and near-fatal asthma (NFA)/fatal asthma studies. Data adapted from references $4,21,23,25,31,33$ and 36

hospital conferred a higher risk of NFA/FA $(\mathrm{OR}=2.62,95 \% \mathrm{CI}$ 1.04 to $6.58, \mathrm{P}=0.04$ ) (Figure 5).

Intensive care unit admission

Two studies, which included 169 patients, examined admission to the intensive care unit (ICU) and found that this conferred a higher risk of NFA/FA (OR=5.14, 95\% CI 1.91 to 13.86 , $\mathrm{P}=0.001$ ) (Figure 6).

\section{Mechanical ventilation}

Seven studies, which included 1372 patients, identified that a history of mechanical ventilation was associated with a higher risk of NFA/FA (OR=4.74, 95\% CI 2.49 to $9.03, \mathrm{P}=0.0001)$ (Figure 7).

\section{ATOPY}

Two studies, which included 280 patients, examined food $(\mathrm{OR}=0.19,95 \% \mathrm{CI} 0.0018$ to $19.83, \mathrm{P}=0.481)$ and drug atopy ( $\mathrm{OR}=0.81,95 \% \mathrm{CI} 0.13$ to $5.17, \mathrm{P}=0.827$ ) (Figure not shown).

\section{SMOKING}

Two studies, which included 412 patients, examined smoking. The results were negative in terms of the risk of NFA/FA ( $\mathrm{OR}=0.99,95 \% \mathrm{CI} 0.48$ to $2.03, \mathrm{P}=0.968)$ (Figure not shown).

\section{DISCUSSION}

As anticipated, a strong predictor or risk factor for NFA/FA is increased use of medications such as beta-agonists administered via an MDI or by nebulization, oral steroids and oral theophylline. Patients who are hospitalized, as the cases and controls were in the present meta-analysis, may have more severe disease and, thus, tend to require more medications. Surprisingly, the impact of exposure to ICS as measured in a dose-independent fashion to reduce the risk of NFA/FA was equivocal. A history of hospital and/or ICU admissions and 
mechanical ventilation due to asthma also conferred a strong risk of NFA/FA. However, ED assessment did not confer a greater risk of NFA/FA. Smoking and atopy did not increase the risk of NFA/FA.

Two major factors that can significantly affect the validity of case control studies include selection of the control group and exposure history (14). An important limitation in the present study is that although most subjects were matched for age and sex, few were matched for asthma severity. Asthma severity may have confounded the meta-analysis because the cases may have had more severe disease than the controls. However, in response to a paper by Spitzer et al (15) that suggested that increasing doses of beta-agonists may result in death, Ernst et al (16) rigorously attempted to control for severity using the Spitzer data, and concluded that perhaps it does not interfere as much as previously thought and may be of minimal importance when studying patients with NFA or FA. Furthermore, it is very difficult to categorize patients with asthma in a reproducible manner. In 1995, the Global Initiative on Asthma (GINA) (17) proposed categorizing asthma severity into the groups intermittent, mild persistent, intermediate persistent and severe persistent. Unfortunately, this has not translated into a clean tool to be used by epidemiologists because it still remains a challenge to categorize the severity of asthma in a reproducible way, especially given the dynamic and complex nature of the disease. A patient that has suffered a NFA attack may have an intermittent disease following the event, which would not categorize that patient as a severe asthmatic.

Information on medication use was integrated by categorizing each exposure. The three types of exposure identified were admission medications (the patient was asked whether they were taking their prescribed medication; yes or no at the time of admission), frequency (none, occasionally or daily use) and prescription (the total number of patients taking at least one canister obtained from a pharmaceutical registry). Although integration of these medications did not allow for analysis of dose responses, it did allow for analysis of exposure. The patients were asked if they were either taking their medications or not taking their medications before admission or the index event (yes or no answer).

The data analyzed did not show a protective effect of ICS with regard to FA and NFA (as shown in Figure 4, where the OR of 13 studies combined was 1.03). However, Suissa et al (18) found a protective effect when exposure was measured in a more precise manner. This study, the largest and best study to date, included 2747 patients (66 cases and 2681 controls) from the Saskatchewan database. Patients were aged five to 44 years and had used three or more antiasthmatic medications in one year of the six-year study. Death was ascertained from death certificates. The use of a prescription database allowed Suissa et al to explore the dose relationship between ICS use and FA. They showed that the use of more than three canisters of ICS in the previous three months was associated with protection against death due to asthma $(\mathrm{OR}=0.13,95 \% \mathrm{CI} 0.02$ to 0.97$)$, and that there was an association between FA and discontinuation of ICS one to three months prior (OR=4.6, 95\% CI 1.1 to 19.1 ).

Although the work by Suissa et al (18) is the best study to date, it does have limitations. Patients that were recruited had to have received at least three prescriptions for antiasthma medications in any one-year period, which perhaps may not have captured all those patients who could also have died of asthma while receiving none, one or two prescriptions in one year. The second largest of the studies was by Lanes et al (19) and included 903 patients (43 cases and 860 controls) based on all patients with a physician diagnosis of asthma selected from a database of 96,258 patients in the United Kingdom. The source population included patients aged between 10 and 79 years and the outcome of death was based on the death certificate. ICS did not confer a statistically significant protective effect, even after the RR ratio was adjusted for the use of ICS in the previous year (one to six canisters, $\mathrm{RR}=0.7$ [95\% CI 0.2 to 2.9] and greater than seven canisters, $\mathrm{RR}=0.7$ [95\% CI 0.2 to 2.8]). Due to the ages used in the inclusion criteria, this study may have included patients with COPD inadvertently and, thus, may have diluted the protective effect of the ICS; however, it included all patients diagnosed with asthma by a physician. Another issue that arises in both of teh aforementioned data sets $(18,19)$ is the method of determining the outcome. Death certificates were used to confirm asthma as the cause; however, the exact cause of death is uncertain and reliance on clinical judgment at the time of death can be varied, inaccurate and overestimate asthma mortality (20).

Asthma history, such as hospital and/or admission to the ICU and mechanical ventilation, conferred a significant risk of NFA/FA as evidenced by the strongly positive ORs. However, ED assessment was not found to be associated with a greater risk of NFA/FA. Possibly, the most severe asthmatic patients do not come to EDs as a result of psychological reasons, access reasons and the perception of dyspnea. Surprisingly, two studies $(16,21)$ found that smoking did not confer a greater risk of NFA/FA. Ernst et al (16) explained that they may not have shown an association because they studied a younger population than previous studies (22) that found an association in older populations that smoked. These older populations had a higher likelihood of containing patients with COPD.

Health care teams should concentrate their efforts in patients who demonstrate any of the risk factors presented in the present analysis of the literature. Although exposure (doseindependent) to ICS did not demonstrate a clear protective effect against NFA/FA in the meta-analysis, when the effect was measured using a dose-dependent formula, the data corroborates with a protective effect for ICS against FA. In addition, the work by Suissa et al (18) demonstrated that discontinuation of medications increased the chances of a fatal event. Furthermore, it should be emphasized that ICS remain the cornerstone of the treatment of asthma to prevent exacerbations and admission to hospital. Perhaps patients not coming to EDs have a blunted perception of dyspnea and do not come until they require admission. Asthmatic patients with the aforementioned strong predictors should be monitored frequently to anticipate and prevent morbidity and mortality.

FUNDING: This project was funded by the Centre for Clinical Epidemiology and Evaluation. Dr FitzGerald is a Michael Smith Distinguished Scholar recipient and a CIHR-BC Lung Scientist.

\section{REFERENCES}

1. FitzGerald JM, Macklem P. Fatal asthma. Annu Rev Med 1996;47:161-8.

2. FitzGerald JM, Turner MO. Delivering asthma education to special high risk groups. Patient Educ Couns 1997;32:S77-86.

3. Awadh N, Muller NL, Park CS, Abboud RT, FitzGerald JM. Airway wall thickness in patients with near fatal asthma and control groups: Assessment with high resolution computed tomographic scanning. Thorax 1998;53:248-53. 
4. Turner MO, Noertjojo K, Vedal S, Bai T, Crump S, FitzGerald JM. Risk factors for near-fatal asthma. A case-control study in hospitalized patients with asthma. Am J Respir Crit Care Med 1998;157:1804-9.

5. Weir TD, Mallek N, Sanford AJ, et al. beta2-Adrenergic receptor haplotypes in mild, moderate and fatal/near fatal asthma. Am J Respir Crit Care Med 1998;158:787-91.

6. Chagani T, Paré PD, Zhu S, et al. Prevalence of tumor necrosis factor-alpha and angiotensin converting enzyme polymorphisms in mild/moderate and fatal/near-fatal asthma. Am J Respir Crit Care Med 1999;160:278-82.

7. FitzGerald JM, Macklem PT. Proceedings of a workshop on near fatal asthma. Can Respir J 1995;2:113-25.

8. Campbell DA, McLennan G, Coates JR, et al. A comparison of asthma deaths and near-fatal asthma attacks in South Australia. Eur Respir J 1994;7:490-7.

9. Molfino NA, Nannini LJ, Rebuck AS, Slutsky AS. The fatalityprone asthmatic patient. Follow-up study after near-fatal attacks. Chest 1992;101:621-3.

10. Molfino NA, Nannini LJ, Martelli AN, Slutsky AS. Respiratory arrest in near-fatal asthma. N Engl J Med 1991;324:285-8.

11. Kolbe J, Fergusson W, Vamos M, Garrett J. Case-control study of severe life threatening asthma (SLTA) in adults: Psychological factors. Thorax 2002;57:317-22.

12. Standards for the diagnosis and care of patients with chronic obstructive pulmonary disease (COPD) and asthma. This official statement of the American Thoracic Society was adopted by the ATS Board of Directors, November 1986. Am Rev Respir Dis 1987;136:225-44.

13. Borenstein M, Rothstein H. Comprehensive Meta-Analysis: A Computer Program for Research Synthesis. Englewood: Biostat, 1999.

14. Schulz KF, Grimes DA. Case-control studies: Research in reverse Lancet 2002;359:431-4.

15. Spitzer WO, Suissa S, Ernst P, et al. The use of beta-agonists and the risk of death and near death from asthma. N Engl J Med 1992;326:501-6.

16. Ernst P, Habbick B, Suissa S, et al. Is the association between inhaled beta-agonist use and life-threatening asthma because of confounding by severity? Am Rev Respir Dis 1993;148:75-9.

17. Global Strategy for Asthma Management and Prevention. NIH Publication No 02-3659. Management Segment (chapter 7): Updated 2004. < www.ginasthma.org/GuidelineItem.asp?intld=82> (Version current July 25, 2005).

18. Suissa S, Ernst P, Benayoun S, Baltzan M, Cai B. Low-dose inhaled corticosteroids and the prevention of death from asthma. N Engl J Med 2000;343:332-6.

19. Lanes SF, Garcia Rodriguez LA, Huerta C. Respiratory medications and risk of asthma death. Thorax 2002;57:683-6.

20. Sears MR, Rea HH, de Boer G, et al. Accuracy of certification of deaths due to asthma. A national study. Am J Epidemiol $1986 ; 124: 1004-11$.
21. Boulet LP, Deschesnes F, Turcotte H, Gignac F. Near-fatal asthma: Clinical and physiologic features, perception of bronchoconstriction, and psychologic profile. J Allergy Clin Immunol 1991;88:838-46.

22. Marquette $\mathrm{CH}$, Saulnier F, Leroy $\mathrm{O}$, et al. Long-term prognosis of near-fatal asthma. A 6-year follow-up study of 145 asthmatic patients who underwent mechanical ventilation for a near-fatal attack of asthma. Am Rev Resp Dis 1992;146:76-81.

23. Strunk RC, Mrazek DA, Fuhrmann GS, LaBrecque JF. Physiologic and psychological characteristics associated with deaths due to asthma in childhood. A case-controlled study. JAMA 1985;254:1193-8.

24. Crane J, Flatt A, Jackson R, et al. Prescribed fenoterol and death from asthma in New Zealand, 1981-83: Case-control study. Lancet 1989;1:917-22.

25. Limthongkul S, Wongthim S, Udompanich V, Charoenlap P, Nuchprayoon C. Status asthmaticus: An analysis of 560 episodes and comparison between mechanical and non-mechanical ventilation groups. J Med Assoc Thai 1990;73:495-501.

26. Kolbe J, Fergusson W, Vamos M, Garrett J. Case-control study of severe life threatening asthma (SLTA) in adults: Demographics, health care, and management of the acute attack. Thorax 2000;55:1007-15.

27. Tanihara S, Nakamura Y, Matsui T, Nishima S. A case-control study of asthma death and life-threatening attack: Their possible relationship with prescribed drug therapy in Japan. J Epidemiol 2002;12:223-8

28. Kikuchi Y, Okabe S, Tamura G, et al. Chemosensitivity and perception of dyspnea in patients with a history of near-fatal asthma. N Engl J Med 1994;330:1329-84.

29. Barboni E, Peratoner A, Rocco PL, Sabadini P. Near fatal asthma and psychopathological characteristics: A group-control study. Monaldi Arch Chest Dis 1997;52:339-42.

30. Tough SC, Hessel PA, Ruff M, Green FH, Mitchell I, Butt JC. Features that distinguish those who die from asthma from community controls with asthma. J Asthma 1998;35:657-65.

31. Hessel PA, Mitchell I, Tough S, et al. Risk factors for death from asthma. Prairie Provinces Asthma Study Group. Ann Allergy Asthma Immunol 1999;83:362-8.

32. Mitchell I, Tough SC, Semple LK, Green FH, Hessel PA. Near-fatal asthma: A population-based study of risk factors. Chest 2002;121:1407-13.

33. Dhuper S, Maggiore D, Chung V, Shim C. Profile of near-fatal asthma in an inner-city hospital. Chest 2003;124:1880-4.

34. Suissa S, Blais L, Ernst P. Patterns of increasing beta-agonist use and the risk of fatal or near-fatal asthma. Eur Respir J 1994:7:1602-9.

35. Rea HH, Scragg R, Jackson R, Beaglehole R, Fenwick J, Sutherland DC. A case-control study of deaths from asthma. Thorax 1986;41:833-9.

36. de Klerk A, van Schalkwyk E, Williams Z, Lee W, Bardin P. Risk factors for near-fatal asthma - a case-control study in a Western Cape teaching hospital. S Afr Med J 2002;92:140-4. 


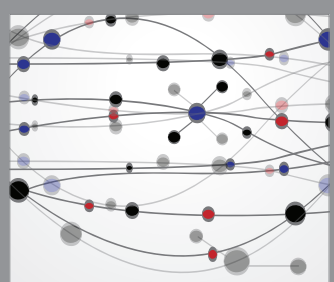

The Scientific World Journal
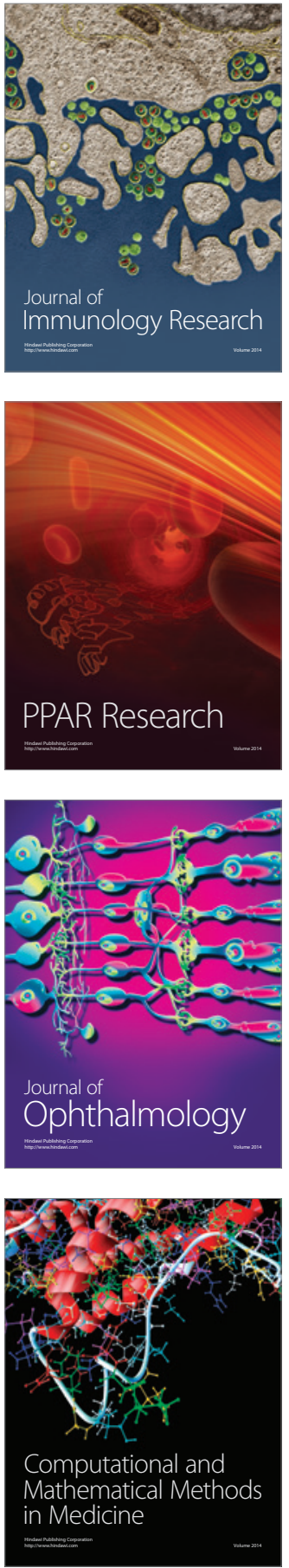

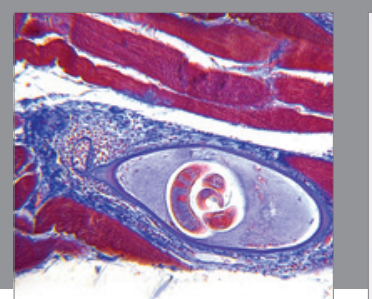

Gastroenterology Research and Practice

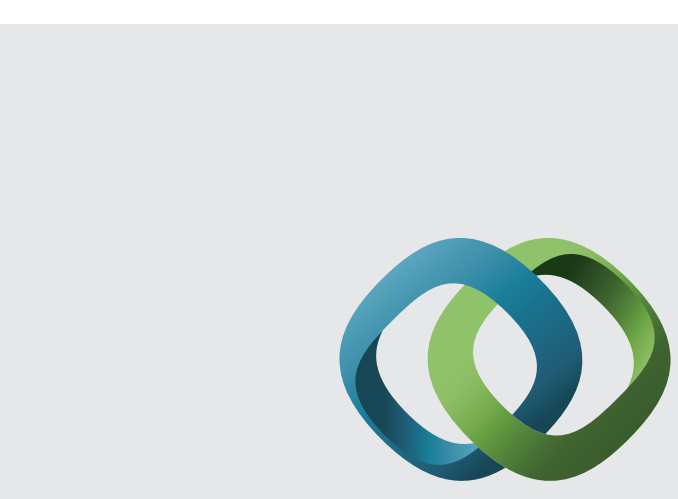

\section{Hindawi}

Submit your manuscripts at

http://www.hindawi.com
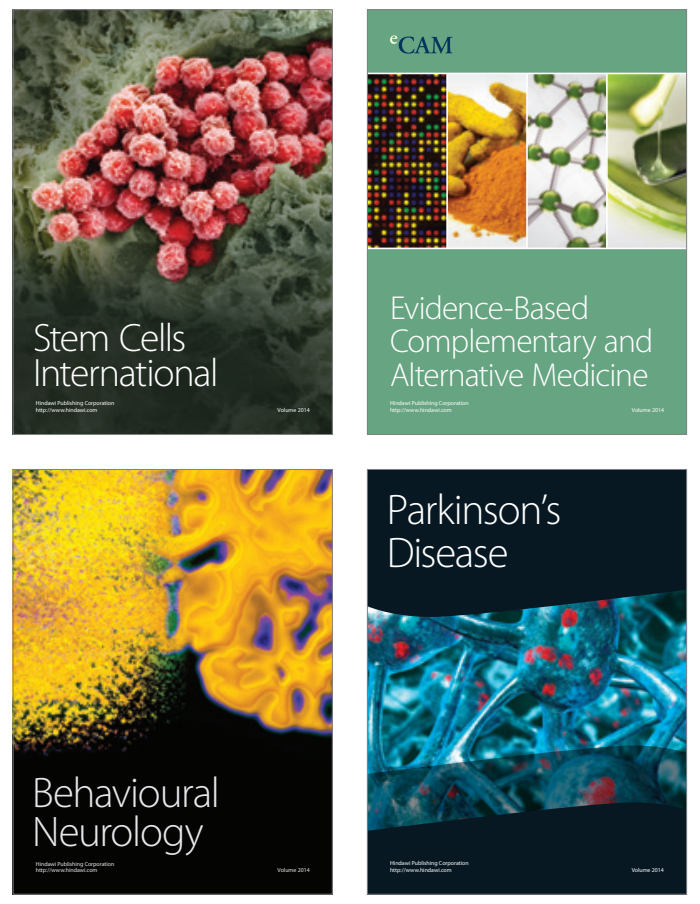
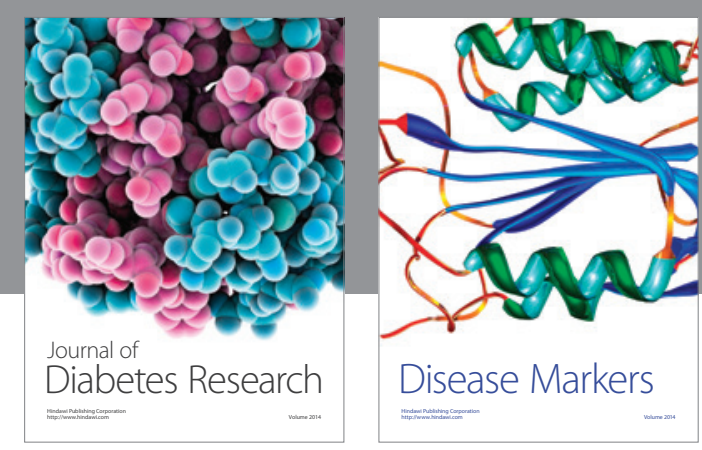

Disease Markers
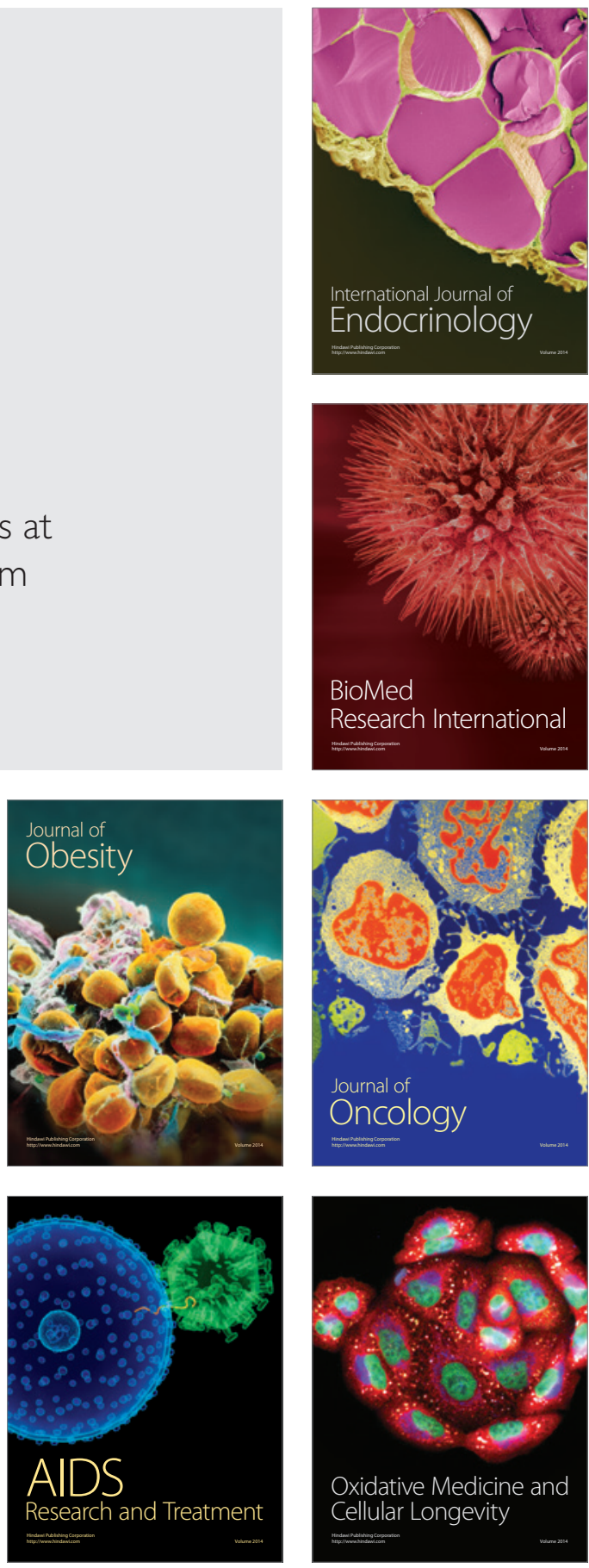